\section{Nádia Kunkel}

Walter Ferreira de Oliveira

Marco Aurélio Peres

\section{Overweight and health-related quality of life in adolescents of Florianópolis, Southern Brazil}

Programa de Pós-Graduação em Saúde Pública. Centro de Ciências da Saúde Universidade Federal de Santa Catarina. Florianópolis, SC, Brasil

\author{
Correspondence: \\ Nádia Kunkel \\ Centro de Ciências da Saúde, Programa de \\ Pós-Graduação em Saúde Pública \\ Universidade Federal de Santa Catarina \\ Campos Universitário Trindade \\ 88040-970 Florianópolis, SC, Brasil \\ E-mail: nadiakunkel@gmail.com
}

\begin{abstract}
OBJECTIVE: To assess health- related quality of life and its association to excess weight in adolescents.

METHODS: Cross-sectional study including 467 adolescents aged 15 to 18 years enrolled in a public school in Florianopolis, Southern Brazil, and their parents, conducted in 2007. Overweight and obesity were defined according to the body mass index. The combination of overweight and obesity was defined as excess body weight. Health-related quality of life was assessed using the Pediatric Quality of life Inventory (PedsQL) 4.0 for adolescents and their parents. Descriptive statistics and unadjusted and adjusted logistic regression analyses were performed.
\end{abstract}

RESULTS: The response rate was $99.4 \%$ among adolescents and $53.4 \%$ among their parents. The prevalence of overweight was $12.2 \%$ and obesity was $3.6 \%$. The group of adolescents with excess weight had lower health-related quality of life when compared with those who were not excess weight, except for the emotional domain in the adolescents, and the psychosocial health domain for the parents. After adjusting, adolescents with excess weight were $3.54(95 \%$ CI 1.4;6.47) folds more likely to have low quality of life than those with no excess weight. Female adolescents had lower quality of life scores.

CONCLUSIONS: Health-related quality of life was significantly lower in adolescents with excess weight excess. Public health actions directed to weight control in adolescents and instruments for quality of life measures are major instruments for a better thorough understanding of this important public health problem.

DESCRIPTORS: Adolescent. Overweight. Obesity. Quality of Life. Questionnaires, utilization. Adolescent Health. Cross-Sectional Studies.

\section{INTRODUCTION}

Obesity is a public health concern worldwide affecting children, adolescents, adults, and the elderly. ${ }^{19}$ In Brazil the prevalence of excess body weight (overweight plus obesity) in adolescents increased from $2.6 \%$ to $11.8 \%$ in boys and from $5.8 \%$ to $15.3 \%$ in girls between 1975 and $1997 .{ }^{17}$ Based on the same classification criteria, the Family Budget Survey (POF) conducted by the Brazilian Institute of Geography and Statistics (IBGE) in 2002-20003 found a prevalence of $23.6 \%$ and $17.1 \%$ of overweight and $3.3 \%$ and $2,9 \%$ of obesity in same-age male and female adolescents, respectively, in urban areas of southern Brazil. ${ }^{a}$ A 2003 study including school adolescents in the city of Florianópolis reported $12 \%$ prevalence of overweight. ${ }^{5}$

a Brazilian Institute of Geography and Statistics. Household Budget Survey 2002-2003. Análise da disponibilidade domiciliar de alimentos e do estado nutricional no Brasil. Rio de Janeiro; 2004 [cited 2006 Jun 14]. Available from: http://www.ibge.gov.br/home/estatistica/populacao/ condicaodevida/pof/2003medidas/pof2003medidas.pdf 
It is estimated that $50 \%$ of obese children will become obese adults. ${ }^{14}$ In addition, they are very likely to develop other related conditions such as diabetes mellitus, cardiovascular diseases, atherosclerosis, arterial hypertension, orthopedic and joint disorders, skin diseases, and higher surgical risk, among other complications. ${ }^{2}$

Increased prevalence of excess body weight during childhood and adolescence has stirred renewed interest in the study of psychosocial outcomes of these conditions at this age group because they may have major psychosocial consequences. ${ }^{20} \mathrm{~A}$ critical time point for the development of obesity is early adolescence, ${ }^{8}$ a life phase when adolescents have constant concern about their body weight, envisaging an ideal of beauty, imposed by the lean, slender body type. Non-acceptance of one's own body can make adolescents feel socially marginalized. ${ }^{20}$

Studies on health-related quality of life (HRQL) in obese individuals have become increasingly common. Most have investigated adults but those few focusing on adolescents have showed a strong consistent association between low HRQL and obesity. ${ }^{9,11,21}$ Further studies are needed in this population in Brazil. A search conducted in Medline, Lilacs, and Scielo database in July 2006 did not find any Brazilian study investigating weight and HRQL issues in adolescents.

To test the hypothesis that HRQL is lower among adolescents with excess body weight compared to their peers with non-excess body weight, the objective of the present study was to assess quality of life of adolescents and its association with excess body weight.

\section{METHODS}

A cross-sectional analytical study was carried out in students attending a public high school in the city of Florianópolis, southern Brazil, in 2007. The sample size was estimated considering a 1:4 ratio of exposed/nonexposed (excess body weight/non-excess body weight) and negative HRQL of $15 \%$ in non-exposed and $30 \%$ in exposed. To that it was added $20 \%$ to compensate losses and refusals. The sample had $80 \%$ power at a $95 \%$ level of confidence. Sample selection was proportional to the number of students enrolled in each grade. A systematic sampling was carried out in each class.

The inclusion criteria were: being under the age of 18 and enrolled in the study school. There were excluded pregnant adolescents and those with physical disabilities that prevented or affected anthropometric measures. Of about 2,400 students enrolled in the high school program, 470 were drawn to participate in the study.
The outcome was HRQL measured using the Pediatric Quality of Life Inventory (PedsQL) 4.0, validated in Brazil. ${ }^{a}$ This questionnaire has a module format designed to assess HRQL of children and adolescents aged between two and 18 years. ${ }^{15}$ It was conceived to measure scores of physical, mental, and social health dimensions as described by the World Health Organization and taking into consideration their school functioning as well. ${ }^{16} \mathrm{~A}$ self-administered PedsQL for adolescents aged between 13 and 18 years was used. It comprised 23 items divided into four domains: physical, emotional, social and school functioning. Table 1 describes the items of each domain. This instrument consists of two parallel questionnaires, one for adolescents and one for parents. This latter was designed to assess parents' perception of their children HRQL.

Quality of life was measured through psychometric analysis using a five-point Likert scale: $0=$ never was a problem; 1 = almost never; $2=$ sometimes; $3=$ frequently; 4 = always). Items were scored, and linearly converted into a 0 to 100 scale $(0=100 ; 1=75 ; 2=$ $50 ; 3=25$; and $4=0$ ). All items were then summed up and divided by the number of questions answered. The higher the score, the better the quality of life. ${ }^{16}$

Besides the PedsQL scale, partial physical (physical health subscale) and psychosocial health (mean emotional, social, and school subscales) scales were measured. ${ }^{15}$

Excess body weight (overweight plus obesity) was measured using the body mass index $(\mathrm{BMI}=$ weight $[\mathrm{kg}] /$ height $\left[\mathrm{m}^{2}\right]$ ) by gender and age. The classification criterion applied for the diagnosis of overweight and obesity was based on the BMI cutoff $\geq 25 \mathrm{~kg} / \mathrm{m}^{2}$ for adults (Cole et $\mathrm{al}^{3}$ ). Weight was measured using a digital scale (Tanita) with $150-\mathrm{kg}$ capacity and $0.2-\mathrm{kg}$ precision that was regularly checked. Measures were taken with subjects in the standing position wearing light clothing and preferably barefoot. When a subject did not agree to be barefoot, there were subtracted from the weight measured $500 \mathrm{~g}$ of footwear for males and $250 \mathrm{~g}$ for females. All data were collected by a skilled nutritionist with experience in anthropometric measures. Height was self-referred by adolescentes ${ }^{6,7}$ because the pilot study showed that adolescents had difficulty referring their weight but not their height.

There were collected independent and control variables using self-administered complementary questionnaires: gender, age, self-referred skin color, living situation (with whom they lived).

The following variables were investigated among parents: family head schooling, child morbidity, family socioeconomic condition (per capita income in reais in the month prior to the interview).

a Klatchoian DA. Confiabilidade da versão brasileira do questionário genérico de qualidade de vida pediátrica versão 4.0 (pedsql 4.0 ) [doctorate thesis]. São Paulo: Universidade Federal de São Paulo; 2007. 
The questionnaires were pre-standardized and pre-tested in 25 students (and one of their parents - mother or father - or guardian) attending $10^{\text {th }}$ grade of a secondary public school. After due adjustments, a pilot study comprising 130 students of two public state schools in the city of Florianópolis was carried out to test the study procedures and standardize anthropometric measures. Instead of self-referred weight it was opted for measuring it since most adolescents did not know their weight.

Subjects filled out the study questionnaires in the classroom. At that time questionnaires were also handed to their parents and they were asked to return them on the next day.

The questionnaires were then coded and reviewed and data was entered using Epi Data program. Data analysis was performed using SPSS for Windows version 10.0 .

Those adolescents who completed less than $50 \%$ of the HRQL instrument were excluded from the analysis.

It was set a cutoff of one standard deviation below the mean score of non-excess body weight subjects and low HRQL was then dichotomized. ${ }^{11}$ Descriptive statistics were used to summarize all variables studied and the associations between outcome and exploratory variables were tested using the chi-square test and ANOVA. Additionally, paired comparison of normal weight, overweight, and obesity groups was performed using the Mann-Whitney U test. Those variables with p-value $\leq 0.20$ were selected and included in the multiple model. Nonconditional logistic regression analysis was carried out stratified by gender. The variables were included in the model in an ascending order by their statistical significance in the chi-square test. Odds ratio (OR) was the measure of effect used to estimate the likelihood of adolescents with excess body weight to have different HRQL than those with non-excess body weight. Crude and adjusted ORs were estimated and variables with $\mathrm{p}<0.05$ after adjustment were considered significantly associated. Simple linear correlation analysis was carried out between total PedsQL scores reported by adolescents and BMI values for the entire sample and stratified by gender.

The study was approved by the Research Ethics Committee of Universidade Federal de Santa Catarina and complied with ethical principles.

\section{RESULTS}

A total of 467 adolescents (99.4\% of the sample) participated in the study. Two adolescents were excluded due to physical disabilities that prevented anthropometric measurements and one was excluded from the analysis because he did not complete at least $50 \%$ of PedsQL. All their parents received the questionnaire and 251 completed it ( $46.3 \%$ response rate).

Mean total HRQL score reported by adolescents whose parents answered the questionnaire was 74.78 (standard deviation [SD]: 12.00) while mean score among those whose parents did not complete the questionnaire was 76.66 (SD: 11.66), a difference that was not statistically significant $(\mathrm{p}>0.05)$. There were $34(13.6 \%)$ adolescents

Table 1. Description of PedsQL 4.0 instrument items in each domain.

\begin{tabular}{ll}
\hline Physical domain & Emotional domain \\
\hline 1 item for each one of the following subjects & Feeling fear \\
Difficulty to walk more than a block & Feeling sad or depressed \\
Difficulty to run & Feeling angry \\
Difficulty to engage in sports activities & Difficulty to sleep \\
Difficulty to lift weight & Self-concern \\
Difficulty to bath by himself/herself & \\
$\begin{array}{l}\text { Difficulty to help with household tasks } \\
\text { Pain }\end{array}$ & \\
Lack of energy & School domain \\
\hline Social domain & Attention difficulty \\
\hline item for each one of the following topics & Memory difficulties \\
Problem or difficulty to interact with peers & Difficulty to follow classroom activities \\
Problem or difficulty to make friends & 2 items on reasons for missing school \\
Difficulty to do the same things other adolescents do & \\
Difficulty to follow same-age adolescents & \\
\hline
\end{tabular}

Source: Adapted from Klatchoian DA. Confiabilidade da versão brasileira do questionário genérico de qualidade de vida pediátrica versão 4.0 (pedsql 4.0) [doctorate thesis]. São Paulo: Universidade Federal de São Paulo; 2007. 
Table 2. Frequencies of demographic and nutritional variables according to sex among high school adolescents. Florianópolis, Southern Brazil, 2007.

\begin{tabular}{|c|c|c|c|c|}
\hline \multirow[b]{2}{*}{ Variable } & \multicolumn{4}{|c|}{$N(\%)$ of subjects } \\
\hline & $\begin{array}{c}\text { Total } \\
(\mathrm{N}=467)\end{array}$ & $\begin{array}{c}\text { Males } \\
(\mathrm{N}=173)\end{array}$ & $\begin{array}{l}\text { Females } \\
(\mathrm{N}=294)\end{array}$ & p-value \\
\hline Age (years) & & & & $0.532 *$ \\
\hline 15 & $187(40.0)$ & $69(39.9)$ & $118(40.0)$ & \\
\hline 16 & $164(35.1)$ & $56(32.4)$ & $108(36.7)$ & \\
\hline 17 & $93(19.9)$ & $39(22.5)$ & $54(18.4)$ & \\
\hline 18 & $23(4.9)$ & $9(5.2)$ & $14(4.8)$ & \\
\hline Nutritional status & & & & $0.291 *$ \\
\hline Non-excess body weight & $393(84.2)$ & $138(79.8)$ & $255(86.7)$ & \\
\hline Overweight & $57(12.2)$ & $31(17.9)$ & $26(8.8)$ & \\
\hline Obese & $17(3.6)$ & $4(2.3)$ & $13(4.4)$ & \\
\hline Skin color & & & & 0.095 \\
\hline White/ yellow & $333(71.5)$ & $132(76.3)$ & $201(68.6)$ & \\
\hline Indian/ black/ mixed & $133(28.5)$ & $41(23.7)$ & $92(31.4)$ & \\
\hline Living situation & & & & 0.974 \\
\hline With both parents & $321(68.7)$ & $121(69.9)$ & $200(68.0)$ & \\
\hline With mother only & $114(24.4)$ & $41(23.7)$ & $73(24.8)$ & \\
\hline With father only & $12(2.6)$ & $4(2.3)$ & $8(2.7)$ & \\
\hline Other & $20(4.3)$ & $7(4.0)$ & $13(4.4)$ & \\
\hline
\end{tabular}

* p-value of linear trend

with excess body weight among those whose parents completed the questionnaire and 40 (18.5\%) among those whose parents did not complete it, a difference that was also not significant $(\mathrm{p}=0.18)$.

Demographic and nutritional characteristics of adolescents are presented in Table 2. Mean age was 15.9 years (SD: 0.89 ) and females were $63.0 \%$ of the sample studied. The prevalence of overweight and obesity was $12.2 \%$ and $3.6 \%$, respectively. Male adolescents had higher prevalence of overweight than females (17.9\% and $8.8 \%$, respectively) while obesity was higher among females ( $4.4 \%$ versus $2.3 \%$ ), but these differences were not statistically significant. There were no significant differences between males and females by age, skin color, and living condition.

As for parental schooling, $2.8 \%$ of family heads were illiterate, $10.0 \%$ had at least four years of schooling, $28.3 \%$ at least eight years, and $56.6 \%$ nine years or more. Mean per capita income was R\$ 424.15.
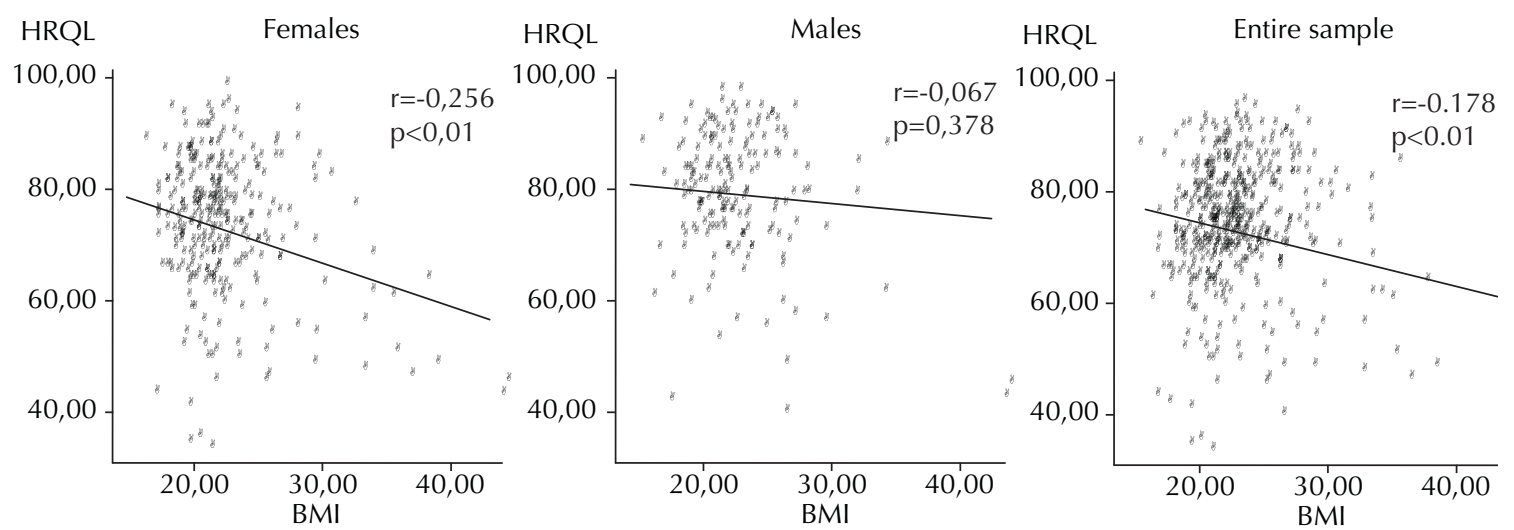

HRQL: Health-Related Quality of Life BMI: Body mass index

Figure. Correlation between health-related quality of life and body mass index by sex among high school adolescents. Florianópolis, Southern Brazil, 2007. 
Table 3 shows a significant difference between excess and non-excess weight groups in all HRQL domains except the emotional one. As for parents' perception, total and physical score significantly varied between the groups studied. The paired comparison analysis using the Mann-Whitney $U$ test showed that the difference between non-excess body weight and overweight group was not significant. However, the comparison between non-excess body weight and obesity group revealed a significant difference in all domains $(\mathrm{p}<0.05$ for the emotional domain and $\mathrm{p}<0.01$ for all others). The comparison between overweight and obesity groups showed a significant difference in the total and physical health domains $(\mathrm{p}<0.01)$, psychosocial and school $(p<0.05)$ but not significant in all others. According to the parents' perception, there was no significant difference in the paired comparison of all domains.

Mean total PedsQL scores of adolescents and their parents/guardians for the entire sample, non-excess, and excess body weight subjects were compared by gender, age, skin color, and living situation (Table 4). Female adolescents had significantly lower HRQL than males. And among parents, child's mixed and black skin color was associated to low quality of life.

After dichotomizing HRQL scores (cutoff value: 65.43 ) into low and adequate, it was found $13.0 \%$ of low HRQL in the non-excess body weight and 29.3\% in the excess body weight group. Table 5 presents ORs stratified by gender and adjusted for age, skin color, and living situation. Female adolescents with excess body weight were significantly more likely to report low HRQL than those with non-excess body weight in all domains, except the emotional one. As for the parents' perception, a significant difference was seen in the total physical and social score. With respect to male adolescents, this difference remained significant only for the total scale score in the self-report and for the physical domain in their parents' perception.

BMI values had a negative correlation with total PedsQL scores reported by adolescents (Figure). Higher correlation was seen among female adolescents $(r=$ -0.256 in females and $r=-0,067$ in males). Only the correlation coefficient between BMI and HRQL in the entire sample and among female adolescents was statistically significant $(\mathrm{p}<0.01)$.

\section{DISCUSSION}

The present study findings indicate a significant association between excess body weight and low HRQL in school adolescents under 18 in the city of Florianópolis. HRQL scores measured using PedsQL were higher in non-excess body weight, followed by overweight and obese adolescents. It suggests a positive association between severity of excess body weight and low quality of life. Adolescents with excess body weight had lower HRQL not only in the total scale score but also in the physical, psychosocial, social, and school domains compared to their peers with non-excess body weight, which suggests this condition has a global impact on the adolescent's daily life. Apart from the emotional domain, the study findings are consistent with those of recent American studies using the same instrument. They reported obese children and adolescents under treatment had lower HRQL in all domains (physical, emotional, social, and school) compared to their peers with normal weight. ${ }^{11,21}$ Similar scores were described

Table 3. Means and standard deviations of total and PedsQL subscale scores reported by adolescents and their parents by nutritional status of high school adolescents. Florianópolis, Southern Brazil, 2007.

\begin{tabular}{lcccc}
\hline Variable & & Mean (SD) & & \\
& Non-excess body weight & Overweight Obese & Excess body weight & p-value \\
\hline Adolescent $(\mathrm{N}=467)$ & & & & \\
Total scale score & $76.44(11.0)$ & $74.02(14.3)$ & $62.90(14.9)$ & $<0.001$ \\
Physical health & $81.76(13.7)$ & $78.30(17.6)$ & $61.79(22.5)$ & $<0.001$ \\
Health psychosocial & $73.68(11.5)$ & $71.75(14.4)$ & $63.56(12.9)$ & 0.002 \\
Emotional & $61.30(17.8)$ & $61.56(18.4)$ & $53.82(18.3)$ & 0.237 \\
Social & $87.77(12.6)$ & $83.28(17.3)$ & $77.87(13.8)$ & 0.001 \\
School & $71.86(15.3)$ & $70.00(17.7)$ & $59.12(13.6)$ & 0.004 \\
Parents (N=251) & & & & 0.021 \\
Total scale score & $80.85(12.4)$ & $76.20(16.9)$ & $69.25(18.0)$ & 0.006 \\
Physical health & $83.83(16.2)$ & $76.06(21.9)$ & $67.41(19.7)$ & 0.141 \\
Psychosocial health & $79.25(12.8)$ & $76.52(15.4)$ & $70.24(17.4)$ & 0.380 \\
Emotional & $70.36(18.5)$ & $65.58(21.2)$ & $65.00(21.4)$ & 0.093 \\
Social & $90.23(13.5)$ & $87.02(13.8)$ & $80.00(20.2)$ & 0.211 \\
School & $77.06(16.1)$ & $76.92(21.3)$ & $65.71(17.9)$ & \\
\hline
\end{tabular}

a ANOVA 
Table 4. Means and standard deviations of total and PedsQL subscale scores reported by adolescents and their parents according to socioeconomic and demographic variables by nutritional status of high school adolescents. Florianópolis, Southern Brazil, 2007.

\begin{tabular}{|c|c|c|c|}
\hline \multirow{2}{*}{ Variable } & \multicolumn{3}{|c|}{ Mean (SD) } \\
\hline & Total & Non-excess body weight & Excess body weight \\
\hline \multicolumn{4}{|c|}{ Total scale score - adolescents $(\mathrm{N}=467)$} \\
\hline \multicolumn{4}{|l|}{ Gender } \\
\hline Male & $79.47(10.62)^{* *}$ & $80.29(9.57)^{* *}$ & $76.22(3.71)^{* *}$ \\
\hline Female & $73.40(12.01)$ & $74.35(11.19)$ & $67.20(5.13)$ \\
\hline \multicolumn{4}{|l|}{ Age (years) } \\
\hline 15 & $76.16(11.35)^{\mathrm{a}}$ & $76.78(10.80)^{\mathrm{a}}$ & $72.34(3.94)^{\mathrm{a}}$ \\
\hline 16 & $74.73(12.26)$ & $76.23(10.74)$ & $65.49(6.63)$ \\
\hline 17 & $76.11(11.88)$ & $75.96(11.78)$ & $76.68(2.58)$ \\
\hline 18 & $76.24(13.42)$ & $77.01(12.55)$ & $74.04(6.74)$ \\
\hline \multicolumn{4}{|l|}{ Skin color } \\
\hline White/Yellow & $75.86(11.65)^{\mathrm{a}}$ & $76.29(11.32)^{\mathrm{a}}$ & $73.50(3.17)^{\mathrm{a}}$ \\
\hline Indian/ Black/ Mixed & $75.17(12.47)$ & $76.89(10.23)$ & $66.96(18.14)$ \\
\hline \multicolumn{4}{|l|}{ Living situation } \\
\hline With both parents & $76.09(11.47)^{\mathrm{a}}$ & $76.64(10.78)^{\mathrm{a}}$ & $72.71(14.75)^{\mathrm{a}}$ \\
\hline With mother only & $75.06(12.17)$ & $76.28(11.01)$ & $69.67(15.55)$ \\
\hline With father only & $73.80(11.79)$ & $77.64(8.49)$ & $68.42(14.57)$ \\
\hline Other & $73.07(16.20)$ & $73.53(15.44)$ & $70.47(23.96)$ \\
\hline \multicolumn{4}{|c|}{ Total scale score - parents $(\mathrm{N}=251)$} \\
\hline \multicolumn{4}{|l|}{ Gender } \\
\hline Male & $85.51(10.78)^{* *}$ & $86.38(9.57)^{* *}$ & $81.50(15.03)^{* *}$ \\
\hline Female & $77.77(13.56)$ & $78.73(12.77)$ & $70.32(17.24)$ \\
\hline \multicolumn{4}{|l|}{ Age (years) } \\
\hline 15 & $82.13(12.90)^{\mathrm{a}}$ & $83.00(11.59)^{\mathrm{a}}$ & $71.17(18.40)^{\mathrm{a}}$ \\
\hline 16 & $78.80(12.90)$ & $79.67(12.28)$ & $71.50(17.29)$ \\
\hline 17 & $78.48(13.58)$ & $79.81(12.85)$ & $70.91(16.19)$ \\
\hline 18 & $75.89(16.68)$ & $74.35(16.71)$ & $91.30(-)$ \\
\hline \multicolumn{4}{|l|}{ Skin color } \\
\hline White/ Yellow & $81.47(12.68)^{* *}$ & $81.82(12.39)^{\mathrm{a}}$ & $79.20(14.52)^{*}$ \\
\hline Indian/ Black/ Mixed & $76.40(14.18)$ & $78.47(12.34)$ & $62.79(18.47)$ \\
\hline \multicolumn{4}{|l|}{ Living situation } \\
\hline With both parents & $80.77(12.60)^{\mathrm{a}}$ & $81.45(12.17)^{\mathrm{a}}$ & $74.71(15.58)^{\mathrm{a}}$ \\
\hline With mother only & $78.70(15.04)$ & $79.98(13.64)$ & $73.40(19.50)$ \\
\hline With father only & $79.35(3.87)$ & $80.43(3.92)$ & $76.09(-)$ \\
\hline Other & $79.18(10.43)$ & $77.60(9.7)$ & $93.48(-)$ \\
\hline
\end{tabular}

$* \mathrm{p}<0.05$

$* * \mathrm{p}<0.01$

${ }^{a}$ non-significant

in a study with children and adolescents diagnosed with cancer. ${ }^{11}$ The non-significant difference in the emotional domain may be associated to the fact that adolescence is a stage of major changes, conflicts, and lack of selfconfidence, which makes adolescents more vulnerable to social and cultural contradictions involving body image-related emotional issues.
The adolescents' parents studied reported a slightly higher HRQL compared to that self-perceived by excess and non-excess body weight subjects. Total and physical domain scores obtained from parents were also significantly lower among those with excess body weight. This finding contrasts with that found in clinical studies of obese adolescents reporting parental perception of 
Table 5. Odds ratio and 95\% confidence interval of low health-related quality of life among excess and non-excess body weight male and female high school adolescents. Florianópolis, Southern Brazil, 2007

\begin{tabular}{ccc}
\hline Variable & Male & Adjusted $\mathrm{OR}^{\mathrm{a}}(95 \% \mathrm{Cl})$ \\
\hline Adolescent $(\mathrm{N}=467)$ & & \\
$\quad$ Total scale score & $2,94(1,12-7,73)$ & $4,59(2,16-9,74)$ \\
$\quad$ Physical health & $1.87(0.73 ; 4.79)$ & $3.08(1.42 ; 6.68)$ \\
Psychosocial health & $1.52(0.64 ; 3.63)$ & $3.14(1.49 ; 6.59)$ \\
Emotional & $1.33(0.54 ; 3.26)$ & $2.32(0.98 ; 5.52)$ \\
Social & $1.59(0.65 ; 3.91)$ & $3.33(1.45 ; 7.62)$ \\
School & $1.45(0.61 ; 3.47)$ & $2.32(1.08 ; 4.98)$ \\
Parents (N=251) & & \\
Total scale score & $4.83(0.88 ; 26.5)$ & $2.59(1,23 ; 5,44)$ \\
Physical health & $5.73(1.2 ; 27.43)$ & $2.78(1.31 ; 5.93)$ \\
Psychosocial health & $2.23(0.42 ; 11.8)$ & $2.04(0.99 ; 4.23)$ \\
Emotional & $1.41(0.29 ; 6.89)$ & $2.01(0.99 ; 4.11)$ \\
Social & $1.84(0.36 ; 9.40)$ & $2.28(1.09 ; 4.77)$ \\
School & $0.67(0.10 ; 4.38)$ & $1.89(0.92 ; 3.88)$ \\
\hline
\end{tabular}

adjusted by age, skin color, and living situation.

their children's HRQL to be lower than that reported by the adolescents. ${ }^{11,21}$ These American studies found significantly lower scores in all domains for obese adolescents according to their parents' perception. ${ }^{11,21}$ However, the results of the present study are consistent with those of another study with schoolchildren where parents reported higher HRQL scores. ${ }^{18}$ The differences found between clinical and school samples suggest that parents have greater concern, care, and interest regarding their children's daily life routine and behaviors as they start a clinical treatment.

In the present study, mean total scale score of obese subjects was similar to that reported by Zeller \& Modi $^{21}$ and Schwimmer et $\mathrm{al}^{11}$ in United States studies with clinical samples. Williams et a ${ }^{18}$ reported contrasting results in a population-based study with elementary schoolchildren in Victoria, Australia. Compared to studies with clinical samples, they found smaller differences between overweight and obese children and those with normal weight. An adequate comparison is not possible as there are no Brazilian studies with clinical samples. But the predominance of female adolescents in the sample studied that showed significantly lower HRQL than males may explain lower total scores found.

When mean total HRQL scores self-reported by adolescents and perceived by their parents were stratified by gender, a significant difference was seen. Quality of life of female adolescents compared to that of males was lower among both excess weight and non-excess weight groups. These results are expected since many studies have shown that female adolescents have greater concern with their body image. ${ }^{4,10}$ Branco et al, ${ }^{1}$ in a study conducted in São Paulo investigating body perception and satisfaction among adolescents and their association with nutritional status, reported body image dissatisfaction was more prevalent among overweight and obese adolescents, especially among females, as well as greater dissatisfaction among eutrophic adolescents.

Parents' perception also revealed a significant difference in mean total scale score by skin color. Parents perceived non-white children as having lower HRQL than white ones. This finding may indicate greater sensitivity to discrimination by the parents that is projected onto their children. However, it cannot be properly inferred as it is out of the scope of the present study.

HRQL is intended to assess overall physical and psychosocial functioning. ${ }^{13,15}$ Although not designed to explore all domains that may be particularly associated to obesity, this instrument can provide an overall picture of how obese people perceive their health and well-being. HRQL assesses major aspects of health that are not covered by conventional physiological and clinical dimensions.

The present study has some limitations. There may have been errors regarding self-referred height, most likely overestimating it and therefore underestimating overweight and obesity. In addition, it was not checked when height was last measured and how it was measured. But studies have shown that self-referred weight and height in adolescents are valid measures. ${ }^{6,7}$ In addition, morbid conditions and socioeconomic conditions were not controlled for as this information was not properly provided by parents/guardians. The classroom was 
not the most adequate environment for the instrument administration as it was noisy and may have disturbed adolescents' concentration. Also, being close to their peers may have made adolescents embarrassed.

A comparison between schooling of Florianópolis population in $1996^{\mathrm{a}}$ and that of family heads of the adolescents studied showed similarities. IBGE data ${ }^{\mathrm{b}}$ showed that, in $1996,39.6 \%$ of adults aged 20 to 59 years had at least eight years of schooling compared to $38.3 \%$ in the present study. Mean per capita income was $\mathrm{R} \$ 424.15$, which is lower than $\mathrm{R} \$ 701.40$ seen in Florianópolis in 2000 . $^{\mathrm{b}}$ It suggests that the study population had lower socioeconomic condition that the average population living in Florianópolis, thus preventing further extrapolation of results citywide.

Despite these limitations, the study generated relevant findings and corroborated other international studies: excess body weight significantly affects the quality of life of adolescents, especially girls. The instrument administered proved to be easy to use and provided consistent results. The study findings stress the importance of assessing HRQL before, during, and after obesity management. This measure can be used as a parameter to assess effectiveness of obesity management. It can also help understand the consequences of obesity in adolescents and support public policies targeting this specific population as well. The instrument administered to parents is a useful tool to evaluate and promote family involvement.

Ravens-Sieberer et al ${ }^{12}$ claim that interventions targeting obese children and their families would require better understanding of life aspects that are most affected by obesity. HRQL assessment can help health providers better understand these aspects. These authors ${ }^{12}$ conclude that HRQL evaluation of obese children is a major tool for assessing treatment success.

It is recommended to further investigate HRQL in population-based and clinical samples of adolescents and in other age groups and to assess depression in this population as well.

\section{ACKNOWLEDGEMENTS}

To the school administration and staff of Instituto Estadual de Educação, Florianópolis, Brazil, for their support. To Prof. Dr Eleonora d'Orsi and Dr Francisco de Assis Vasconcelos, of Universidade Federal de Santa Catarina, for their suggestions.

\footnotetext{
a Brazilian Ministry of Health. Banco de Dados do Sistema Único de Saúde (DATASUS) [internet]. [cited 2007 Aug 12]. Available from: http:// tabnet.datasus.gov.br/cgi/deftohtm.exe?ibge/cnv/estsc.def.

${ }^{\mathrm{b}}$ Brazilian Institute of Geography and Statistics. 2000 Population Census. Rio de Janeiro; 2001.
} 


\section{REFERENCES}

1. Branco LM, Hilário MOE, Cintra IP. Percepção e satisfação corporal em adolescentes e a relação com seu estado nutricional. Rev Psiquiatr Clin. 2006;33(6):292-96. DOI: 10.1590/S010160832006000600001

2. Carneiro JRI, Kushnir MC, Clemente ELS, Brandão MG, Gomes MB. Obesidade na adolescência: fator de risco para complicações clínico-metabólicas. Arq Bras Endocrinol Metab. 2000;44(5):390-96. DOI:10.1590/S0004-27302000000500005

3. Cole TJ, Bellizzi MC, Flegal KM, Dietz WH. Establishing a standard definition for child overweight and obesity worldwide: international survey. BMJ. 2000;320(7244):1240-3. DOI: 10.1136/ bmj.320.7244.1240

4. Conti MA, Frutuoso MFP, Gambardella AMD. Excesso de peso e insatisfação corporal em adolescentes. Rev Nutr. 2005;18(4):491-7. DOI: 10.1590/S1415-52732005000400005

5. Farias JFJ, Lopes AS. Prevalência de sobrepeso em adolescentes. Rev Bras Ci e Mov. 2003;11(3):77-84.

6. Farias Jr JC. Validade das medidas auto-referidas de peso e estatura para o diagnóstico do estado nutricional de adolescentes. Rev Bras Saude Mater Infant. 2007;7(2):167-74. DOI: 10.1590/S151938292007000200007

7. Goodman E, Hinden BR, Khandelwal S. Accuracy of teen and parental reports of obesity and body mass index. Pediatrics. 2000;106(1 Pt 1):52-8. DOI: 10.1542/peds.106.1.52

8. Muller RCL. Obesidade na adolescência. Pediatr Mod. 2001;37(n esp):45-8.

9. Pinhas-Hamiel O, Singer S, Pilpel N, Fradkin A, Modan D, Reichman B. Health-related quality of life among children and adolescents: associations with obesity. Int J Obes (Lond). 2006;30(2):267-72. DOI: 10.1038/sj.ijo.0803107

10. Rand CS, Resnick JL. The "good enough" body size as judged by people of varying age and weight. Obes Res. 2000;8(4):309-16. DOI: 10.1038/ oby. 2000.37
11. Schwimmer JB, Burwinkle TM, Varni JW. Healthrelated quality of life of severely obese children and adolescents. JAMA. 2003;289(14):1813-9. DOI: 10.1001/jama.289.14.1813

12. Ravens-Sieberer U, Redegeld M, Bullinger M. Quality of life after in-patient rehabilitation in children with obesity. International J Obes Relat Metab Disord. 2001;25(Supl 1):S63-5. DOI: 10.1038/sj.ijo.0801702

13. Testa MT, Simonson DC. Assessment of quality of life outcomes. N Engl J Med. 1996;334(13):835-40. DOI: 10.1056/NEJM199603283341306

14. Vanhala M, Vanhala P, Kumpusalo E, Halonen P, Takala J. Relation between obesity from childhood to adulthood and metabolic syndrome: population based study. BMJ. 1998;317(7154):319.

15. Varni JW, Seid M, Rode CA. The PedsQI ${ }^{\mathrm{TM}}$ : Measurement model for the pediatric quality of life inventory. Med Care. 1999;37(2):126-39. DOI: 10.1097/00005650-199902000-00003

16. Varni JW, Seid M, Kurtin PS. The PedsQI ${ }^{\mathrm{TM}} 4.0$ : Reliability and validity of the pediatric quality of life inventory version 4.0: generic core scales in healthy and patient populations. Med Care. 2001;39(8):80012. DOI: $10.1097 / 00005650-200108000-00006$

17. Veiga GV, Cunha AS, Sichieri R. Trends in overweight among adolescents living in the poorest and richest regions of Brazil. Am J Public Health. 2004;94(9):1544-8. DOI: 10.2105/AJPH.94.9.1544

18. Williams J, Wake M, Hesketh K, Maher E, Waters E. Health-related quality of life of overweight and obese children. JAMA. 2005;293(1):70-6. DOI: 10.1001/ jama.293.1.70

19. World Health Organization. Obesity: preventing and managing the global epidemic. Geneve; 1998.

20. Zametkin AJ, Zoon CK, Klein HW, Munson S. Psychiatric aspects of child and adolescent obesity: A review of the past 10 years. I Am Acad Child Adolesc Psychiatr. 2004;43(2):134-50. DOI: 10.1097/00004583-200402000-00008

21. Zeller MH, Modi AC. Predictors of health-related quality of life in obese youth. Obesity (Silver Spring). 2006;14(1):122-30. DOI: 10.1038/oby.2006.15

Article based on N Kunkel's master's dissertation submitted at the Postgraduate Program in Public Health, Universidade Federal de Santa Catarina, in 2007.

N Kunkel was supported by Coordination for the Improvement of Higher Education Personnel (CAPES; master's scholarship). 